\section{Laying the guidelines bare}

The long, tortuous process of setting controls on experiments involving recombinant DNA in the United States has taken yet another potentially important turn. Colin Norman reports

THE National Institutes of Health (NIH), the agency responsible for supporting most recombinant DNA experiments in the United States, last week published a 100-page document analysing the possible effects of the safety guidelines which it issued last June. Publication of the document, a legal requirement under the terms of the National Environmental Policy Act (NEPA), is likely to provide an important means of gathering public opinion on the guidelines, but it could also pave the way for some legal challenges to them.

Links between recombinant DNA research and environmental policy may seem a bit tenuous, but the language of NEPA is clear. It specifies that government actions which could have environmental implications should be preceded by an impact statement detailing the environmental risks and benefits associated with that action. Since microorganisms bearing recombinant DNA molecules could affect the health of plants, animals or man, the issuing of guidelines designed to keep such organisms in the laboratory and out of the general environment clearly comes under the terms of NEPA.

That fact was realised in the NIH while the guidelines were in the late stages of drafting, and caused considerable consternation in the agency, contributing to some delay in publication of the guidelines. In the end, however, Donald S. Fredrickson, Director of the $\mathrm{NIH}$, decided to short-circuit the normal NEPA procedure by publishing the guidelines first and the environmental impact statement later. Therein lies a potential problem for NIH.

Already, NIH has received a number of complaints that Fredickson's action has circumvented public participation in the formulation of the guidelines. Among the complaints is a letter from two researchers at the Friends of the Earth, a national environmental organisation. The researchers, Francine Simring and Larna Saltzman, have asked NIH to stop funding all recombinant DNA experiments until the correct NEPA procedure has been followed, arguing that prior publication of the guidelines violates the spirit as well as the letter of NEPA.
Fredrickson has claimed, however, that prompt publication of the guidelines served the public interest better than following the usual NEPA procedure. Until the NIH guidelines were published on June 23, recombinant DNA experiments were proceeding under general guidelines drafted by an international group of geneticists which met at Asilomar, California, early in 1975. The NIH guidelines are in many respects more stringent than the Asilomar guidelines and they also establish a detailed implementation procedure. Thus, the impact statement itself suggests that "the escape of potentially hazardous organisms was more likely in the absence of NIH action". Though such arguments are rational enough, the possibility of a legal challenge should not be completely ruled out.

Nevertheless, the impact statement provides an important addition to the literature on the regulation of recombinant DNA experiments since it provides the first public discussion of the reasons why NIH chose not to follow some courses of action advocated by various groups and individuals. It also contains a discussion of the possible risks and benefits associated with the research, attempts to estimate the probability that some hazards will be realised, describes the guidelines, and outlines the procedure by which they were adopted.

As far as alternative courses of action are concerned, the statement discusses the following:

- No action-simply continue to rely on the Asilomar guidelines as the basis for regulating recombinant DNA experiments. Such a course was rejected because the Asilomar guidelines are considered too lax in some cases, and because there is no formal mechanism to ensure that they will be followed.

- Prohibition of funding from NIH for recombinant DNA experiments. That suggestion was rejected because other sources of funding are available, the potential benefits from the research would be foreclosed, it would "undermine American leadership in the establishment of worldwide safety standards", and the "leadership of the United States in biological research would be threatened". A flat prohibition would also interfere with free scientific inquiry, the statement suggests.

- Restrict all permissible experiments to a few maximum containment facili- ties-a suggestion put forward most notably by Robert Sinsheimer, Chairman of the Department of Biology at California Institute of Technology. The statement notes that such a course of action would not distinguish between experiments with high potential risk and those believed to pose little, if any, hazard. It would also discourage many experiments and amount to a prohibition on some research because of limited access to such facilities, the statement suggests.

- Prohibit the use of the bacterium $E$. coli in recombinant DNA experiments. Because $E$. coli is a common inhabitant of the human gut, many observers have argued that it is a particularly risky choice as the host for transplanted genes. The statement points out that the particular strain of $E$. coli used in the laboratory has many features which limit its infectiousness. Moreover, it can be genetically altered to reduce its viability even further, as required by the guidelines for some classes of experiments. The statement also defends the decision to permit the use of $E$. coli by noting that no other bacterial species now seems to offer as many safety features.

- The statement also notes that some observers have questioned the decision to permit experiments involving the formation of recombinant molecules from uncharacterised pieces of DNA from warm-blooded animals-so-called shotgun experiments. It also notes that the use of DNA from oncogenic viruses has been challenged. The statement does not defend the decision to permit such experiments, however; instead, it merely notes the objections.

- The environmental impact statement has now been circulated in draft form to numerous scientists and other interested individuals and it is also available on request from the NIH division of environmental services. It is open for comments for 45 days, after which the NIH may convene a series of public hearings. Eventually, the document will be expanded and cast in final form. The comments will also be considered during any future revision of the guidelines.

Because both the risks and the benefits from recombinant DNA experiments are speculative, the impact statement is necessarily vague in places, and is also shot through with value judgments in areas where experimental data are lacking. Critics of the guideline and of the research will therefore find plenty to criticise in the document. A heated and lengthy debate should be anticipated. 